\title{
Portail en ligne FMH Services pour l'emploi et les cabinets
}

\section{Le portail de l'emploi et des cabinets pour \\ - les médecins et \\ - le personnel médical}

Passez vos annonces sur www.fmhjob.ch / www.fmhprax.ch et dans le Bulletin des médecins suisses (BMS).

Publiez vos offres d'emploi et de cabinet sur cette plateforme leader du marché pour attirer l'attention des hôpitaux, des médecins et des entreprises du secteur de la santé.

Vous recherchez un emploi ou un cabinet? Sur www.fmhjob.ch et www.fmhprax.ch, vous trouverez les meilleures offres du marché suisse. Vous disposez d'un compte personnel qui vous permet de gérer vos offres EN LIGNE et d'adresser vos candidatures de manière simple et rapide à l'annonceur.

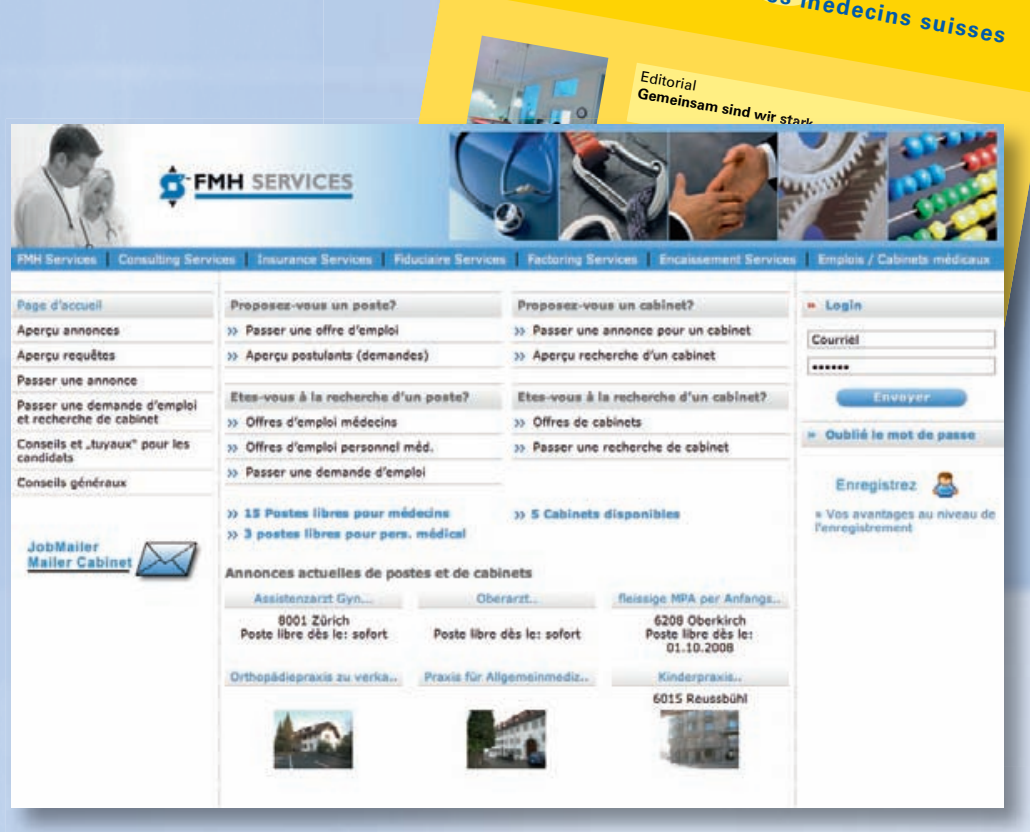

Essayez www.fmhjob.ch et/ou www.fmhprax.ch et laissez-vous convaincre.

\section{www.fmhjob.ch}

\section{Proposer un emploi}

- Compte utilisateur personnel pour une saisie, mutation et gestion simples des annonces

- Optimisation des coûts grâce à la publication combinée Internet-BMS

- Offre chiffrée

- Recherche efficace de collaboratrices/collaborateurs correspondant aux profils dans l'aperçu - rapide et direct avec un abonnement

\section{Rechercher un emploi}

- Recherche simple et sélection d'annonces

- Insertion gratuite de demandes d'emploi: ces annonces ne sont visibles que par les utilisateurs identifiés et enregistrés bénéficiant d'un abonnement

- Tarif préférentiel pour la publication de votre demande dans le Bulletin des médecins suisses, la revue spécialisée la plus lue de ce secteur

- Job-Mailer: recevez les nouvelles offres d'emploi simplement et gratuitement par e-mail

- Saisie, envoi et gestion des candidatures en ligne

- Tri des annonces et création de listes aide-mémoire

- Conseils et astuces pour la recherche d'emploi

\section{www.fmhprax.ch}

\section{Proposer un cabinet}

- Saisie et mutation des annonces à l'aide du compte utilisateur personnel

- Gestion conviviale des annonces et des réponses

- Optimisation des coûts grâce à la publication combinée Internet-BMS

- Offre chiffrée

- Mise en ligne de photos pour une présentation optimale du cabinet

\section{Rechercher un cabinet}

- Compte utilisateur personnel pour une saisie, mutation et gestion simples des annonces et des réponses

- Optimisation des coûts grâce à la publication combinée Internet-BMS

- Offre chiffrée

- Mailer Cabinet: recevez les nouvelles offres de cabinet simplement et gratuitement par e-mail

- Prise de contact simple avec l'annonceur

- Saisie, envoi et gestion des demandes en ligne

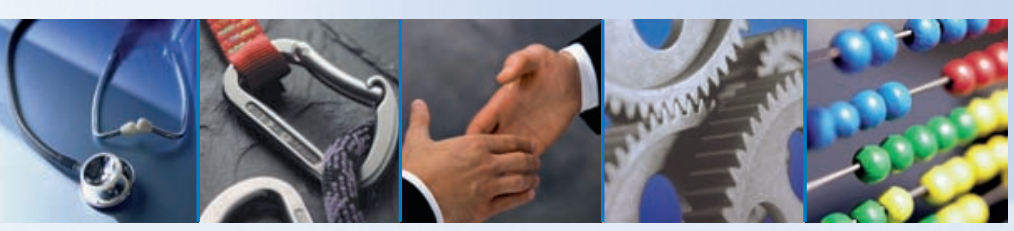

